\begin{tabular}{l}
$\begin{array}{c}\text { Yanbu Journal } \\
\text { of } \\
\text { Engineering } \\
\text { and Science }\end{array}$ \\
\hline \hline ISSN: $1658-5321$
\end{tabular}$\quad$ Vol. 7, October $2013(1434 \mathrm{H})$

\title{
MICROCONTROLLER-BASED ULTRASONIC SENSORS SYSTEM FOR MOBILE ROBOT OBSTACLE AVOIDANCE
}

\author{
Sanaa I. Amer, Osama Arafa, Aziza M. Zaki \\ Electronics Research Institute, Cairo, Egypt
}

\begin{abstract}
The complete contact-less sensory coverage of the workspace represents a fundamental difficulty for the navigation of autonomous mobile systems. Usually, several sensor systems are used in combination which could be complementary or redundant. The task of combining the information into a usable form, suitable for making navigation decisions, is known as sensor fusion. The use of the microcontroller in the robot system gives the opportunity to store a large amount of data gathered about the environment. The algorithms designed for obstacle avoidance during navigation are also easily executed. In this paper, a microcontroller system designed to control the navigation of a mobile robot while avoiding obstacles in its route is presented. A system of 24 ultrasonic sensors was designed and the operation algorithms were described.
\end{abstract}

Keywords: Microcontroller, Ultrasonic Sensors, Mobile Robot.

\section{INTRODUCTION}

Considering the navigation of autonomous mobile systems in only partially known or unknown dynamic environments, the complete contact-less sensory coverage of the workspace represents a fundamental difficulty. Most autonomous robotic systems will have multiple sensors $[1,2]$. Usually several sensor systems are used in combination. There are sometimes complementary, sometimes redundant. Many mobile robots carry sensors for dead reckoning such as optical encoders and geomagnetic sensors together with sensors for map making and self-location such as time-of-flight ultrasonic systems and laserbased ranging systems [3]. In almost all robot systems, multiple sensors from the same type or different types are used to give complete coverage, for example a ring of 24 ultrasonic sensors in $15^{\circ}$ increments around a vehicle, mobile robot CARMEL (Computer-Aided
Robot for Maintenance, Emergency and Life support) [4]. Another example is the Nomad Supper Scout II which carries 16 ultrasonic sensors separated by $22.5^{\circ}$ around the vehicle [5]. The task of combining the information into a usable form, suitable for making navigation decisions, is known as sensor fusion. McKerrow [6] lists several complexities involved in the task of sensor fusion:

- Different sensors measure different parameters (e.g. vision and range data).

- Different physical locations require transformation into common reference.

- Differing time bases due to update times and movement during updates.

- Differing resolutions.

- Sensor noise.

However, during operation of autonomous systems in real environments, objects appear which cannot be in the right time detected by 
any of the employed sensor systems. In such cases tactile sensors serve as safety deactivation, whereas they often also cannot cover the whole potential collision range.

Vision sensors are used in many applications to build an image of the space confronting the mobile robot in order to detect any obstacle and avoid collisions. Vision sensor uses light reflected from objects to model an intensity grid or image of the facing objects. It can be grayscale grids or color grids. Recently most vision sensors can create a color grid image, while data analysis can take place on either grayscale or color grids. Vision systems are usually computational expensive as image formation is too complicated for many applications.

The use of ultrasonic in most applications is easier, cheaper and computationally simpler. Ultrasonic transducers are preferably used to obtain three-dimensional information of the environment [7-10]. They measure and detect distances to moving objects, are impervious to target materials, surface and color. Solid-state units have virtually unlimited maintenancefree lifespan. They also detect small objects over long operating distances and resistant to external disturbances such as vibrations, infrared radiation, ambient noise and EMI radiation. Ultrasonic sensors are not affected by dust, dirt or high-moisture environment. Our objective in this work is to improve the recognition of objects with sonar sensors.

In section 2 of this work, the ultrasonic sensor features and applications are presented. Section 3 presents the system controller requirements according to the system configuration. The distribution of the sonar sensors is also justified. The interface board is described in section 4. Section 5 gives the conclusion extracted from the work.

\section{ULTRASONIC SYSTEMS}

Time-of-flight (TOF) ranging systems measure the round-trip time required for a pulse of emitted energy to travel to a reflecting object, then echo back to a receiver. Using elementary physics, distance is determined by multiplying the velocity of the energy wave by the time required to travel the round-trip distance:

$\mathrm{d}=\mathrm{v} \times \mathrm{t}$

Where: $\mathrm{d}$ is the round-trip distance, $\mathrm{v}$ is the speed of propagation of the pulse and $t$ is the elapsed time. Ultrasonic TOF ranging is today the most common technique employed on indoor mobile robotic systems, primarily due to the ready availability of low-cost systems and their ease of interface. Over the past decade, much research has been conducted investigating applicability in such areas as world modeling and collision avoidance, position estimation, and motion detection. Several researchers have more recently begun to assess the effectiveness of ultrasonic sensors in exterior settings [11-13].

\subsection{TyPES OF UlTRASONIC SENSORS}

We found a lot of different types of ultrasonic sensors. Before we select or install an ultrasonic sensor, we should be familiar with these terms:

1. Dead Zone: Ultrasonic sensors have a "dead" zone in which they cannot accurately detect the target. This is the distance between the sensing face and the minimum sensing range.

2. Beam angle: The beam cone angle values are the $3 \mathrm{~dB}$ points (i.e., points at which the sensor signal is attenuated by at least $3 \mathrm{~dB})$.

3. Beam cone diameter: The ultrasonic sensor emits sound beam in a beam angle cone that eliminates side lobes. Target size 
versus beam spot size is important. Theoretically, the smallest detectable target is one half the wavelength of the ultrasonic signal.

4. Maximum sensing range: Most sensor specifications are based on targets with good reflective characteristics, precise alignment to the target surface and a clear/calm atmosphere at ambient temperature. It is often beneficial to choose a sensor with a maximum range that far exceeds the requirement of the application.

5. Background suppression: Types of ultrasonic sensors differ in the capability of sensing the intended target without sensing material located just behind the target.

6. Switching frequency: The maximum frequency at which the sensor is capable of turning on and off depends on several variables. The most significant are target size, target material and distance to the target.

7. Inclination of target: If a smooth flat target is inclined more than $\pm 3^{\circ}$ to the normal of the beam axis, part of the signal is deflected away from the sensor and the sensing distance is decreased.

8. Environmental considerations:

Temperature range, humidity level, air turbulence, dust affect the operation of the sensor and the range should be defined in the data sheet.

The most commonly used sonar device for mobile robots is the well known Polaroid ultrasonic ranging system. After studying some types of ultrasonic sensors, we selected the (Devantech SRF04 Ranger Compact High Performance Ultrasonic Ranger [14]) for use in this work.
The SRF04 was selected for its compact design, simplicity for interface and above all its moderate price. The unit comprises a transmitter and a receiver in one module.

\subsection{THE POLAROID ULTRASONIC RANGING SYSTEM}

The description and specifications of the SRF04 are following:

\section{a. Description}

This is a fantastic ultrasonic ranger that has an approximate range of $3 \mathrm{~cm}$ to $3 \mathrm{~m}$. This ranger has a logic line used to trigger a pulse and the echo is returned on a second line. Minimal power requirements and a compact, self contained design make this one of the most popular detectors.

This block anodized aluminum housing can hold one SRF04 range finder. All necessary hardware is included. Figure (1) represents the SRF04 ultrasonic sensor.

\section{b. Specifications}

The specifications of SRF04 Ultrasonic Ranger are shown in the appendix. The beam pattern of the SRF04 is conical with the width of the beam being a function of the surface area of the transducers and is fixed. The beam pattern of the transducers used on the SRF04, taken from the manufacturer's data sheet, is shown in figure (2).

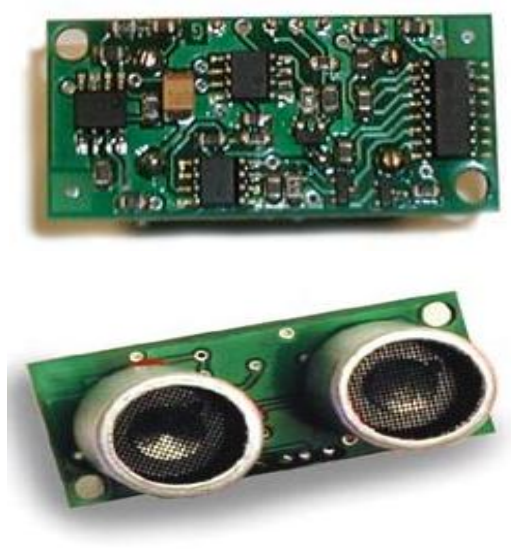

Fig.1. Devantech SRF04 Range. 


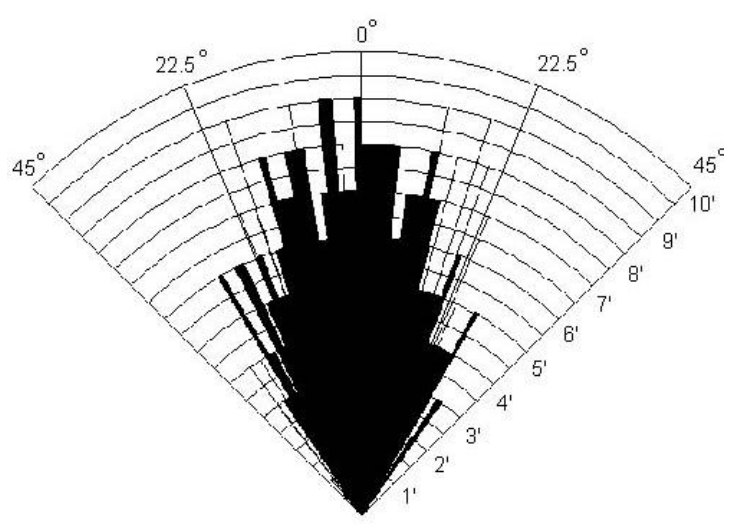

Fig.2. Beam Pattern.

The ranger works by transmitting a pulse of sound outside the range of human hearing. This pulse travels at the speed of sound (roughly $0.9 \mathrm{ft} / \mathrm{m} \mathrm{sec}$ ) away from the ranger in a cone shape and the sound reflects back to the ranger from any object in the path of this sonic wave. The ranger pauses for a brief interval after the sound is transmitted as shown by the simplified waveforms of figure (3), then waits for the reflected sound in form of an echo.

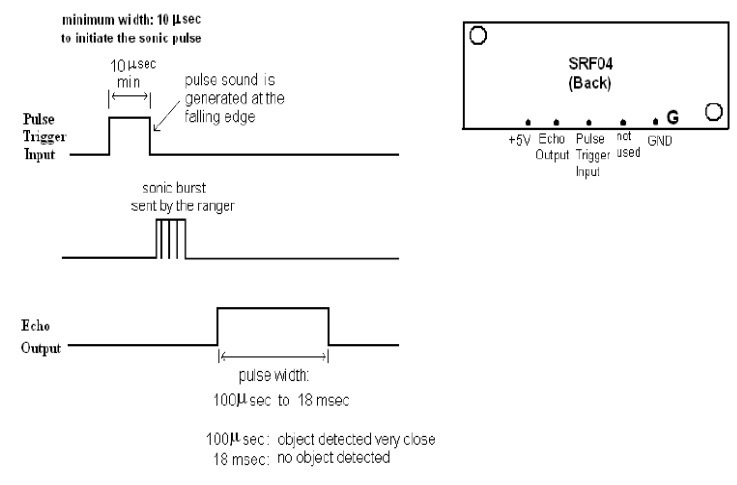

Fig.3. SRF04 Typical waveforms \& connections.

\section{THE PROPOSED CONTROLLER}

The driving system of the robot is composed of 4 wheels each of them equipped with a separate electric motor. A front and rear steering system were added to give flexibility in the motion planning for smooth navigation. The mobile robot configuration is shown in figure (4). The robot is equipped with a

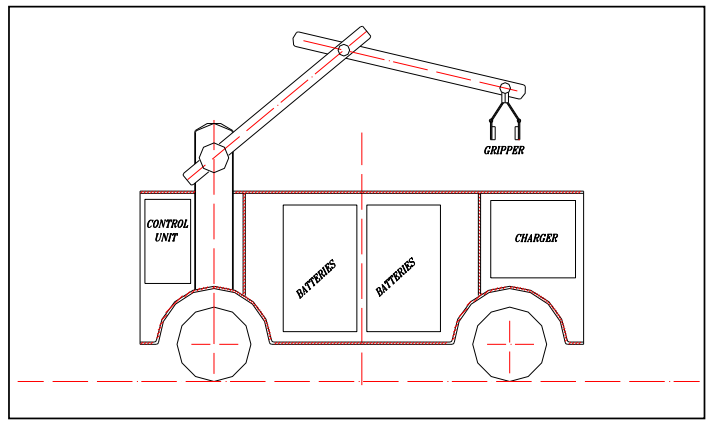

Fig.4. Mobile Robot Configuration.

simple arm used during loading and unloading the components.

At designing a motion controller for an autonomous mobile robot, a main problem must be handled which is the obstacle avoidance problem. To solve this problem we have to answer three questions:

i. How the robot senses the obstacle?

ii. What are the characteristics of the obstacle that the robot will avoid?

iii. What will be the strategy used by the robot to avoid the obstacle?

In the case considered, the robot is moving to transport electronic components from a warehouse to one of three production lines. It is required from the robot to go to certain shelf in the warehouse to pick up some components and then move towards the door as a first step to drive these components to the required assembly line avoiding collision to any obstacle during its motion. The mission of the robot in the inner warehouse is to pick up components from the target point. So, it will be always moving next to one of the walls as the shelves in this warehouse are located next to the walls. Outside the warehouse, the path will be prescribed according to the target production line. The sensors should be arranged so as to achieve safe navigation inside and outside the warehouse. We use a system of 24 ultrasonic sensors arranged around the vehicle as shown in figure (5). 


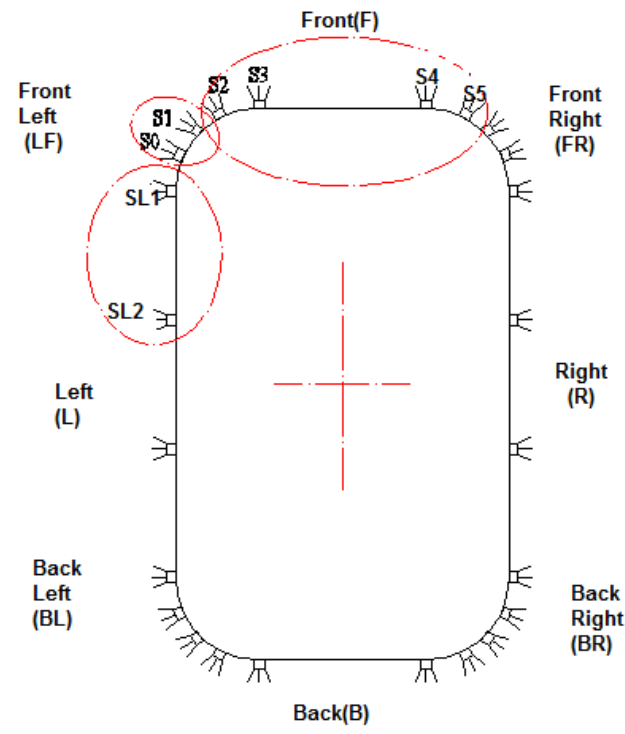

Fig..5. Sensors groups.

\subsection{SENSORS CLUSTERING}

Grouping to the sensors is made to facilitate decision making. The sensors in a certain group act as one sensor (grouped sensor). So the sensors in each group must be selected carefully.

The clustering procedures are as follows:

1. Scan the readings of the sensors of the group.

2. The minimum reading is the dominant one and the others are neglected.

The clustering shown in figure (6) is the suggested one for our controller. Front left (FT): Sensors (So, S1) and Front (F): Sensors (S2, S3, S4 and S5). The robot senses the obstacles using its sonar sensors. Obstacle characteristics can be summarized in the following:

1. Obstacle dynamics: usually the robot can sense both static and dynamic obstacles. In this work, we consider only the static type.

2. Shape and material: don't have great impact in our case.
3. Dimension: the sonar sensors cannot detect obstacles that have height smaller than certain value (indicated in the data sheet), so we consider only obstacles that can be detected by the sonar sensors.

The readings of the grouped sensors are assigned one of two labels which are: far and dangerous. Each group has different interpretation to the meaning of far and dangerous. For example for the front sensors group, the reading of the group ranging from $1 \mathrm{~m}$ to $3 \mathrm{~m}$ is far, while the reading $3 \mathrm{~cm}$ to $1 \mathrm{~m}$ is dangerous.

The selection of the range affects on the sensitivity of the sensors or in other meaning the evaluation to the distance between the robot and the obstacle from the point of view if it is dangerous or not. We need the front sensors to be more sensitive than the FrontRight (FR-RT) and Front- Left (FR-LT) to protect the robot from collision with the walls or obstacles during turning at the walls corner or turning around the obstacle to avoid it. These three groups help the robot to avoid the front obstacles and to turn in the corners and start to align again to a new wall. During backward navigation, Back (B), Back left (BL) and Back right (BR) are the sensors groups used.

\subsection{MOTION INSIDE THE WAREHOUSE}

The difference between the readings of the two side sensors $\Delta \mathrm{L}=\mathrm{SL} 1-\mathrm{SL} 2$ are used to help the robot to align to the left wall. We want the robot to keep certain distance to the wall which is estimated in our work to be 50 $\mathrm{cm}$. The selection of this value is targeted to help the robot to turn smoothly at the corners without getting stuck with the walls. While the other grouped sensors allow the robot to detect the obstacles in his way and avoid collision by rotating around it. The used algorithm (Algorithm1) is shown in figure (6). 
This algorithm is called once entrance to the warehouse is acknowledged and repeated during navigation inside the warehouse.

\section{EXPERIMENTAL TESTING}

\subsection{TESTING OF SRF04 SENSOR OPERATION}

In figure (7), the photograph shows the URF board, a single SRF04 sensor, the testing board and a power supply. They were connected together in a successful testing trial. Line1 is used to display the ranging result and line2 is used to display the sensor ID whose ranging results is displayed in line1. The sensor connection was made with each of the 24 channels and all these channels give satisfactory results.

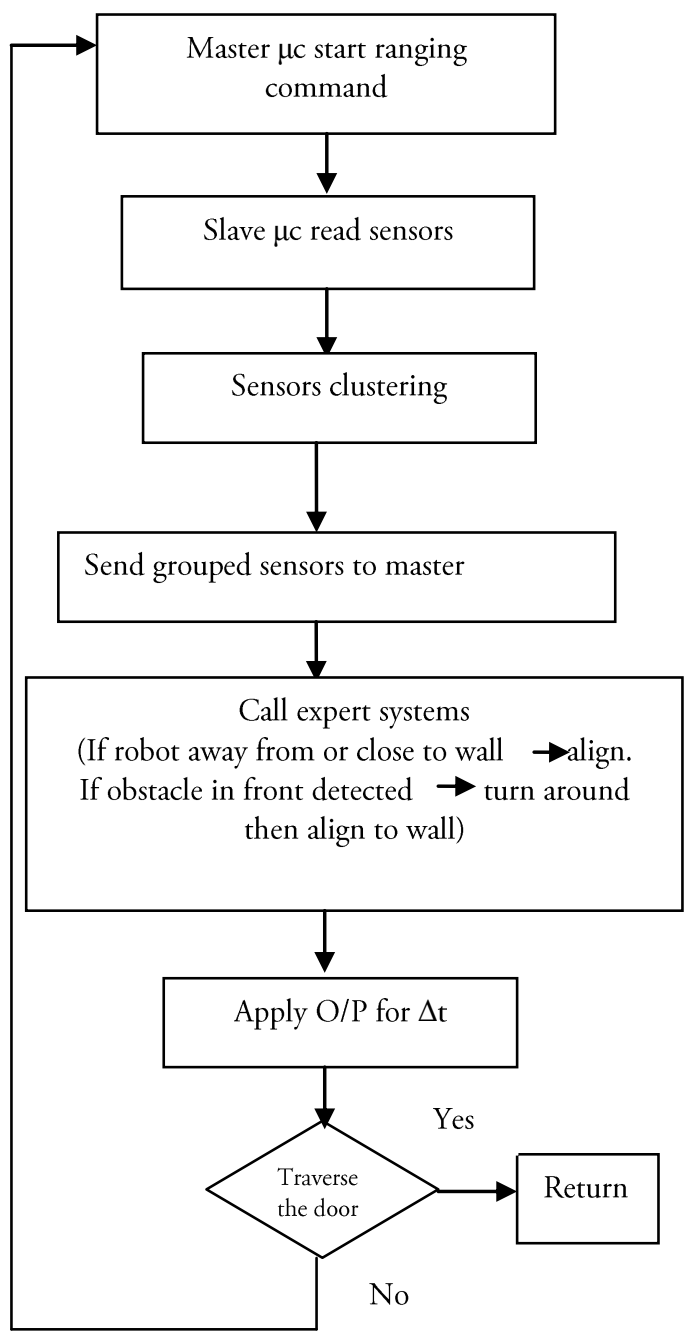

Fig..6. Algorithm1 for inner navigation.

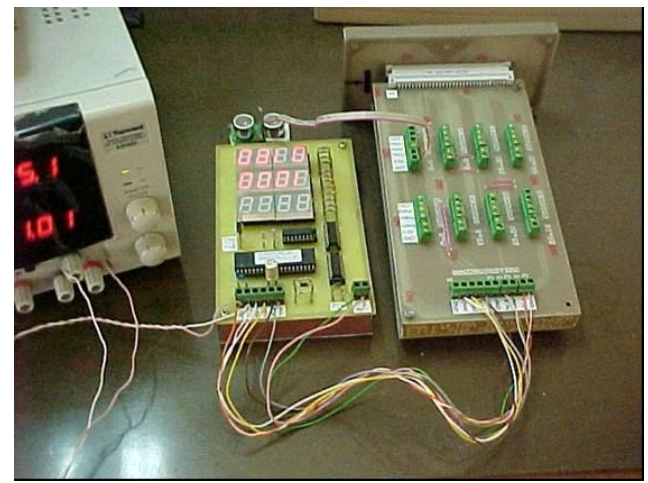

Fig..7. Ranger Testing board, SRF04 sensor and URF board during test

\subsection{THE INTERFACE BOARD}

Since ultrasonic ranging depends on measuring the time duration taken by the ultrasonic wave to travel go and back between the transceiver and the nearest object, it is essential to have a precise means of time measuring which should meet the following requirements:

1. To put a minimum loading on the master microcontroller of the robot to preserve its processing power for the navigation and objects handling tasks.

2. To provide sufficient number of independent time measuring devices that can serve simultaneously as many transceivers as needed by the mobile robot vehicle.

3. Ranging is to be initiated by the master. The ranging subsystem should acknowledge the master upon completion of each individual ranging task.

The first requirement is met by offering a separate microcontroller that can collect the ranging results from the available time measuring devices and convert them from time units to suitable distance units (centimeters, meters or foots), then store them in an array form. The master microcontroller can acquire these data as needed through a master/slave serial communication link. 
The second requirement is met by providing sufficient number of independent counters that can individually and simultaneously count the pulses of a high frequency clock shared by all counters. The planned number of channels in this stage is 24 channels which may more or less fulfill the requirements of the mobile robot.

The third requirement is met by establishing a handshaking link between the master controller and the ranging controller. Through this link a start ranging command is issued by the master and a ranging completed signal is issued by the slave when the latest echo signal of the 24 transceivers is captured.

The main building block beside the Atmel AVR90S8515 microcontroller is a programable TTL counter chip 8254 which has 3 independent counters.

This main building block is repeated eight times to provide a total of 24 timing channels. Since the microcontroller has its own external oscillator $(8 \mathrm{MHz})$, we used one of its internal timers to provide a proper lower frequency clock for the 8254 counters timing task. Also the Serial communication port of the microcontroller is used to transmit ranging results from the AVR90S8515 to the Master robot controller.

ATMEL AVR microcontrollers are easily programmed using the ATMEL integrated development environment AVR studio 4, where assembly programs can be edited, simulated, debugged and downloaded to the microcontroller.

\subsection{Control Architecture OVERVIEW}

The mobile robot control system is a multiinput multi-output large and complex one that may require a dedicated controller for each of its multiple subsystems. For example the robot's wheels need a dedicated motion control system which can receive and execute the following high level motion commands and report execution errors in case of fault incidence.

- Set Forward Speed.

- Set Backward Speed.

- Move Forward X centimeters.

- Move Backward X centimeters.

- Stop Immediately.

- Turn Right Y degrees

- Turn Left Y degrees

- Reset Odometer.

- Get Odometer.

This motion control task is accomplished in parallel to the requirements of obstacle avoidance task. So, the controller system should be able to accomplish simultaneously the right operation of the robot while taking care of the safety of the system.

The ultrasonic ranging subsystem requires a dedicated controller which can accurately report the distances to the nearest objects for all the installed ultrasonic sensors in response to a high level "Range Find" command issued by the robot master.

The software needed for this application comprised two basic sections:

- The down-stream section resides mainly on the slave microcontroller figure (8) and involves the following tasks:

i- Configuring the slave controller's resources to match the application requirements. 
ii- Configuring the 24 counters to work in Mode 0.

iii- Waiting until the Master controller issues a Start Ranging Command.

iv- Initiating the ranging process by issuing a $15 \mu$ s positive strobe to the transceivers then waiting until all echo signals drop to low logic level

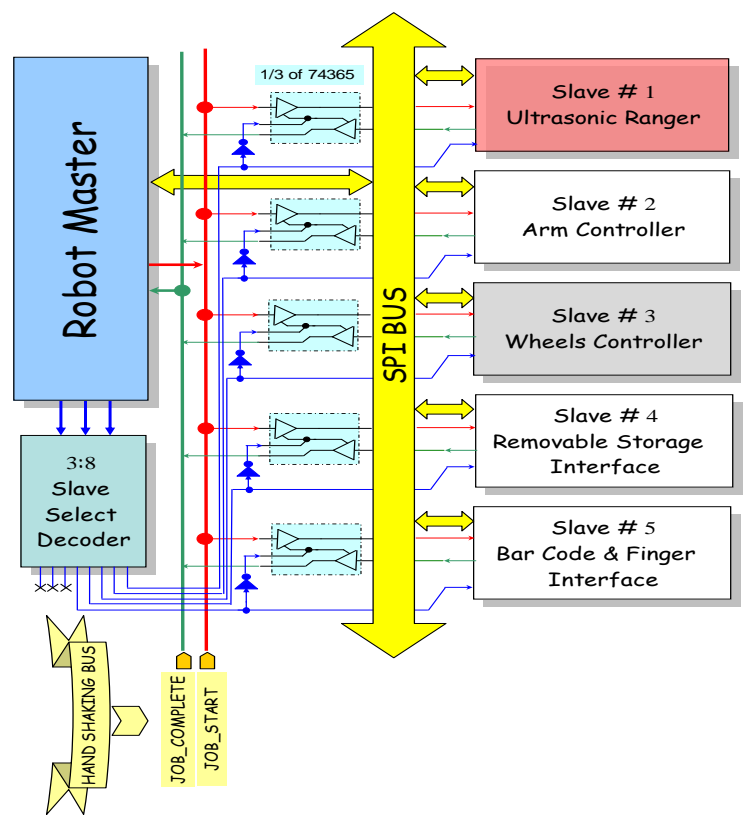

Fig.8. Single Master Multiple Slave Controller Architecture.

v- Reading the count value of all the 24 counters, correcting then converting them to the desired distance units.

vi- Storing the distance values in an array form in which the raw number equals the corresponding transceiver ID number.

vii- Issuing a "Ranging Complete" signal to the master microcontroller then entering a waiting state.

- The up-stream section resides mainly on the master microcontroller and involves:

i- Issuing a "Start Ranging" command to the slave.

ii- Waiting for the "Ranging Complete" acknowledgement from the slave. iii- Initiating a synchronized serial communication session between master and slave upon this acknowledgement.

iv- Acquiring the ranging data from the slave within the serial communication session.

\subsection{Motion Outside The WAREHOUSE}

Over the outer-warehouse, the robot will move in one of three predetermined paths to arrive to one of the three assembly lines. Each line is assigned a name or a number. These paths were saved in the robot memory, example:- Assembly line: point Bo then point B1. Each path is saved as a consequence number of $(x, y)$ points starting from just the warehouse door. So, a look-up table is established to match between the assembly line's number and the sequence of points representing it. In order that the robot can follow a certain path, it has to trace its points in order until reaching its target. The composite behavior will be divided into four primitive behaviors which are:-

1- Path 1 behavior

2- Path 2 behavior

3- Path 3 behavior

4- Obstacle avoidance

Path 1:

1- Move forward 1.5 meters.

2- Turn right 90 degrees

3- Move forward 6 meters

4- Stop

Path 2:

1- Move forward 1.5 meters.

2- Turn left 90 degrees

3- Move forward 17 meters

4- Stop

Path 3:

1 Move forward 1.5 meters.

2- Turn left 90 degrees 
3- Move forward 4 meters

4- Turn left 90 degrees

5- Move forward 8 meters

6- Turn right 90 degrees

7- Move forward 17 meters.

8- Stop

The area of the place was divided as a map of $\mathrm{x}, \mathrm{y}$ points. Point $(0,0)$ is just at the midpoint of the warehouse door. The step was set to be 0.5 meters.

Look-up table representing the 3-pathes will be as follows:-

\begin{tabular}{|c|c|c|}
\hline $\begin{array}{c}\text { Path 1 } \\
\mathrm{x}, \mathrm{y}\end{array}$ & $\begin{array}{c}\text { Path 2 } \\
\mathrm{x}, \mathrm{y}\end{array}$ & $\begin{array}{c}\text { Path 3 } \\
\mathrm{x}, \mathrm{y}\end{array}$ \\
\hline 0,0 & 0,0 & 0,0 \\
0,3 & 0,3 & 0,3 \\
12,3 & $-34,3$ & $-8,3$ \\
Stop & stop & $-8,-13$ \\
& & $-42,-13$ \\
& & stop \\
\hline
\end{tabular}

When the robot terminates the required job at any of the assembly lines, it will take the reverse direction to his path returning back to the door of the warehouse (point $(0,0)$ ). During its navigation, the robot reads continuously the sensors readings. If the robot detects an obstacle in front of him, it will stop and stores its position to avoid the collision and at the same time not to loose its path.

A schematic diagram of the working area is shown in figure (9).

Algorithm2 shown in figure (10) represents the procedure used for robot navigation outside the warehouse.

\subsection{Maneuvering at The Warehouse Door}

The robot system ability to detect obstacles during navigation was tested during maneuvering at the warehouse door while getting in or out the warehouse.

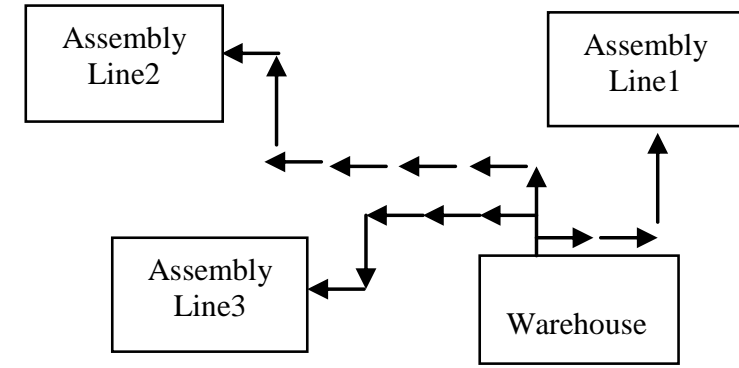

Fig.9. Schematic diagram of the working area

The readings of the ultrasonic sensors indicate if it is in the right position to enter, for example, or not. If the robot detects a part of the wall in the left or right, depending on the set of sensors that detects an obstacle, he has to maneuver to put itself in the right position in front of the door before getting in:-

- First, he has to go backward for about $50 \mathrm{~cm}$.

- Then moving right or left depending on the position detected by the sensors until aligning to the centre of the door.

- During its route to the production line, in many places the ailes are very narrow, so the robot will stop when he detects an obstacle and gives an alarm, so the obstacle could be removed.

This process was tested successfully during testing the robot operation.

\subsection{RESULTS DISCUSSION}

During testing of the robot operation, the robot had to go to one of the assembly lines and get back to the warehouse, it maneuvers to put itself in the right position at the door, go to the target Assembly Line and get back to the warehouse entering safely from the door. Some problems were encountered concerning the maneuvering at the door and the errors were adjusted. These paths were traveled successfully at the end. 


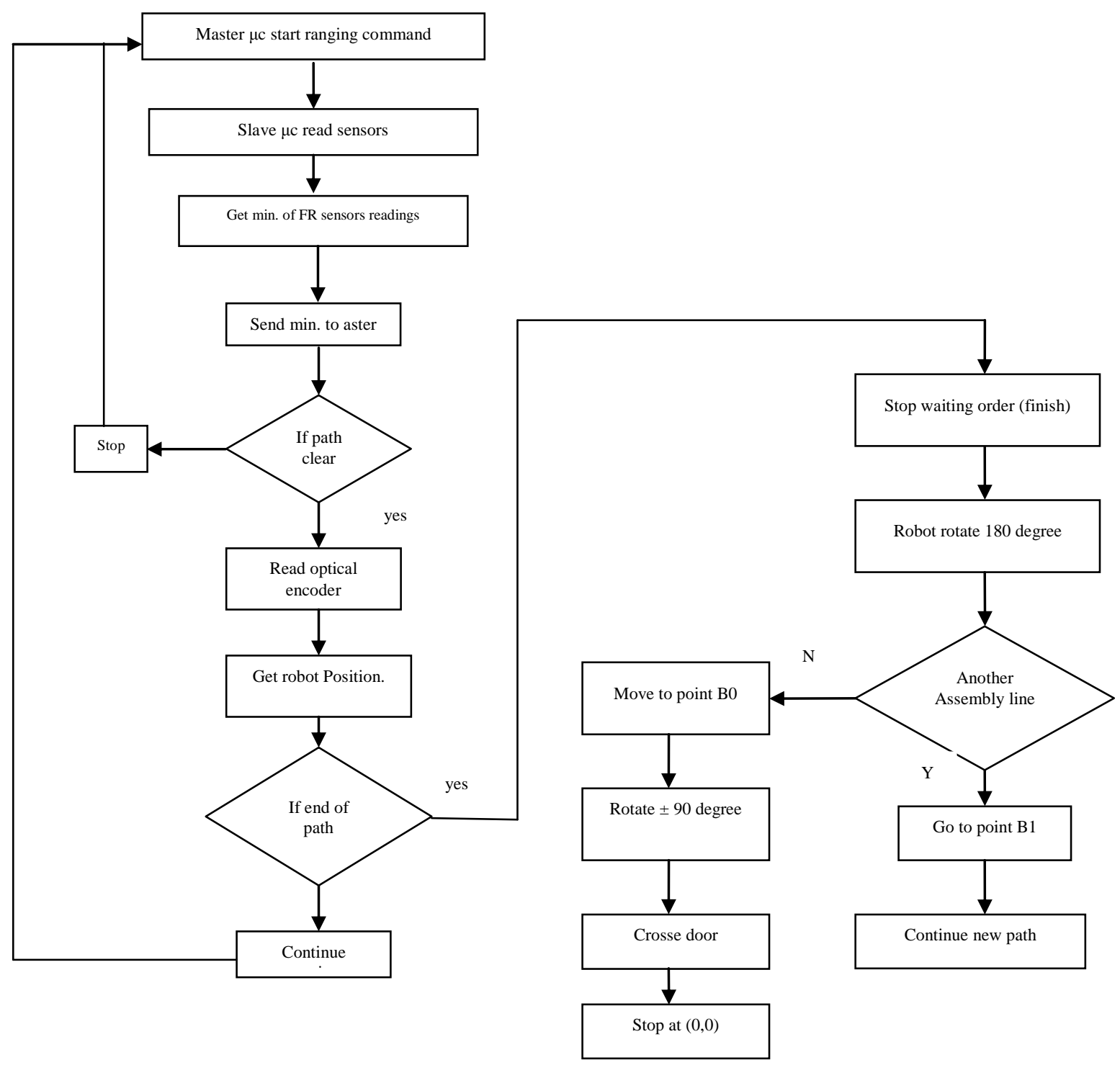

Fig.10. Algorithm2 for outer space navigation

\section{CONCLUSION}

The paper presents the control system of a mobile robot operating to transport components from a warehouse to production lines according to prescribed pathes avoiding collision to any obstacle during its navigation. The robot has to follow the designed algorithm (algorithm1) during moving inside the warehouse to get the required items. Then transporting these items to the prescribed assembly line, it has to follow another algorithm (algorithm2). A microcontroller system was designed to accomplish this task. An ultrasonic ranger slave microcontroller system was designed and programmed to accomplish this task. The ultrasonic sensor used specifications was presented and the number of sensors and their positioning around the robot was designed and illustrated. The system was tested in each step. The ultrasonic sensors was tested first to be sure of the consisting of the readings and the corresponding sensors. Also the paths to the three assembly lines were programmed and stored to be followed by the robot. Obstacle detection was examined. The robot stops when detecting an obstacle and gives an alarm in order to remove it. 


\section{REFERENCES}

[1] R. A. Brooks, "A Robust Layered Control System for a Mobile Robot", IEEE Journal of Robotics and Automation, RA-2, pp 14-23, April 1986.

[2] L.V. Mogensen, "Sensor Fusion for Mobile Robots", M.Sc. Thesis, Technical University of Denmark (DTU), 2006.

[3] M. Kam, Z. Zhu and P. Kalata, " Sensor Fusion for Mobile Robot Navigation", Proceeding of the IEEE, Vol.85, No.1, pp. 108-119, Jan.1997.

[4] J. Borenstem, Y. Koren, "The Vector Field Histogram-Fast Obstacle Avoidance for Mobile Robots", IEEE Journal of Robotics and Automation, Vol.7, No.3, June 1991.

[5] Zou Yi, " Multi-Ultrasonic Sensors Fusion for Autonomous Mobile robots in Confined Spaces", M.Sc. Thesis, Nanyang Technological University, 2001.

[6] P. J. McKerrow, "Introduction to Robotics", Addison-Wesley Publishing Co., Sydney, 1991.

[7] Dirk Bak, "A Novel Ultrasonic Sensing System for Autonomous Mobile Systems", www.morpha.de/download/publications/FAW.I SENSORS 2002.

[8] H.R. Everett, "Sensors for Mobile Robots: theory and Application", A.K. Peters, Ltd. Natich, Massachusetts, 1995.

[9] Johann Borenstein and Yoram Koren, "Obstacle Avoidance with Ultrasonic Sensors " ,IEEE Journal of Robotics and Automation, VOL. 4, No.2, pp.213-218, 1988.

[10] J.S. Benitz-Read and E. Rojas-Ramirez, "Intelligent Control and Sensor Fusion of a Mobile Robot Based Monitoring System", Intech - Mobile Robots Navigation, ISBN: 978-953307-076-6, pp 655-666, 2010.

[11] Pletta et.al, "Part I Sensors for Mobile Robot Positioning", Chapter 4, Langer and Thorpe, 1992.

[12] D.K. Novick, "Implementation of a sensor Fusion-Based Object-Detection Component for an Autonomous Outdoor Vehicle", Ph.D. Thesis, University of Florida, 2002.

[13] W. E. Green, "A Hybrid MAV for Ingress and Egress of Urban Environments ", IEEE Trans. On Robotics, Vol.25, Issue 2, pp.253-263, April 2009.

[14] Polaroid, "Ultrasonic Ranging System", 1987.

\section{APPENDIX}

TABLE (1) SRF04 SPECIFICATIONS.

\begin{tabular}{|l|l|}
\hline Beam Pattern & see graph (figure 2) \\
\hline Voltage & $5 \mathrm{v}$ \\
\hline Current & $30 \mathrm{~mA}$ Typ. 50mA Max \\
\hline Frequency & $40 \mathrm{KHz}$ \\
\hline Maximum Range & $3 \mathrm{~m}$ \\
\hline Minimum Range & $3 \mathrm{~cm}$ \\
\hline Sensitivity & Detect a $3 \mathrm{~cm}$ diameter stick at $>2 \mathrm{~m}$ \\
\hline Input Trigger & $10 \mathrm{uS}$ Min. TTL level pulse \\
\hline Echo Pulse & $\begin{array}{l}\text { Positive TTL level signal, width } \\
\text { proportional to range. }\end{array}$ \\
\hline Weight & 0.4 oz. \\
\hline Size & $4.4 \mathrm{~cm} \times 1.6 \mathrm{~cm} \times 1.27 \mathrm{~cm}$ \\
\hline
\end{tabular}




\title{
استخدام مستشعرات الموجات فوق الصوتية لتجنب العوائق للروبوت عن طريق الاعتماد على الميكروكونترولز
}

\author{
سناء محمد إبر اهيم، اسامة عرفة، عزيزة محمود زكى \\ معهد بحوث الإلكترونيات، القاهرة، جمهورية مصر العربية
}

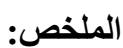

استخدام الحساسات اللاتلامسية فى كامل مجال العمل تمثل صعوبة اساسية اثثاء تجو ال الروبوت المتحرك ذاتى الحركة. وفى العادة يتم استخدام عدد من نظم الحساسات التى يمكن ان تكون متكاملة او متكررة. وفى هذة الحالات فإن تجميع المعلومات فى صورة عملية مناسبة لإتخاذ القرارات أثناء التجوال تعرف بإنصهار الحساسات حيث يمكن استخر اج المعلومات من مجموعة الحساسات كاملة. و استخدام الميكروكونترولرللتحكم فى مسار الروبوت المتحرك يمكن من تخزين كمية كبيره من المعلومات التى يتم تجميعها عن الوسط المحيط اثثاء السير كما تيسر تتفيذ البر امج الخاصة بحركة الروبوت مع تجنب الاصطدام بالأشياء فى محيط السير . وفى هذا البحث تم تصميم نظام لاستخدام الميكروكونترولر فى التحكم فى حركة الروبوت اثثاءالتجوال وتم عرضه مع أستعمال بعض الحساسات التى تم در استها وتم أختيار المناسب منها من حيث النوع و العدد المستخدم الذى ينم وضعها (تثبيتها) ونوزيعها حول الروبوت وتم عمل برامج التحكم حيث يتوقف الروبوت فى حالة اكتشاف عائق حقيقى ويرسل جرس انذار او يتوقف عند إحساسة بالتصادم فيتوقف قبل الاصطدام وقد تم استخدام 24 حساس من الحساسات الفوق صوتية وتم تقيم برنامج عمل الروبوت. 